\title{
Synthesis and Mechanical Reconfiguration of Ground Plane Tilted Microstrip Antennas Based on Tetra-Circle Fractals
}

\author{
Mychael Jales Duarte (1), Valdemir P. da Silva Neto (1) and Adaildo Gomes D’Assunção (1) \\ Federal University of Rio Grande do Norte, UFRN-CT-DCO, Caixa Postal 1655, \\ Natal, RN, Brazil, 59078-970 \\ mychael_duarte@hotmail.com,valdemir.praxedes@ct.ufrn.br,adaildo@ct.ufrn.br
}

\begin{abstract}
A synthesis procedure of a mechanically reconfigurable antenna based on tetra-circle fractal patch elements is presented, enabling to change both resonant frequencies and radiation pattern performance. The antenna geometry reconfiguration is implemented by tilting the ground plane of the microstrip antenna with respect to the fractal patch and substrate layer. The tilt angle is defined as the angle between the back of the dielectric substrate and the tilted ground plane and is electromechanically varied using a thin rod of dielectric material sliding up and down, in a simple geometry. Simulation results for the proposed antenna parameters are obtained using Ansoft HFSS software. In addition to promoting frequency and pattern reconfiguration, the tilting of the ground plane has proven to be an alternative to increase the antenna gain and enable single-band or dual-band operation. Prototypes were fabricated and measured for comparison purpose showing a good agreement between simulation and measurement results.
\end{abstract}

Index Terms - Reconfigurable antenna, mechanically reconfiguration, fractal patch, tetra-circle fractal.

\section{INTRODUCTION}

The modern wireless communication systems have required the development of compact devices, such as printed circuits [1], [2], including microstrip antennas, to perform a large number of service applications with high transmission and reception rates. Typically, a microstrip antenna is composed of a metallic patch printed on a dielectric substrate which is mounted on a ground plane. The shape and dimensions of the metallic patch play an important role on the microstrip antenna performance. Metallic patches with different shapes have been used, including rectangles, triangles, circles, regular polygons, fractals and quasi-fractals.

Over the years, with the advancement of telecommunication systems, many researchers have been working on the development of microwave circuits capable of operating in different frequency bands and whose parameters can be easily changed or reconfigurated [3]-[6]. In [3], the use of reconfigurable antennas is performed to make one antenna works for different systems and applications.

In [4], a reconfiguration based on the use of a liquid actuator as an antenna substrate was proposed. A liquid polymer is placed below the resonator patch and an aluminum structure is placed around the 
patch. When an electrostatic force is applied on the aluminum structure, it goes down, pushing the polymer further towards the center, and consequently, raising the patch. This works as an increase of the substrate thickness and modifies the antenna resonant frequency value.

In [5], a rectangular ring patch antenna is presented, which enables a polarization reconfiguration and small deviation on the resonant frequency. The antenna has two feeders which are composed of coupling patches, an impedance transformer and a variable capacitor. The antenna reconfiguration is provided by the variation of the capacitance value.

A polarization reconfiguration through PIN diodes placed near the antenna's edge, where these diodes make the connections for small patches is proposed in [6]. Depending on whether the diodes are ON (polarized) or OFF (non-polarized), the polarization of the antenna is circular or not, with very small variation on the resonant frequency.

This work proposes a new mechanically reconfigurable patch antenna for wireless communications systems. The patch antenna is based on a fractal shape. Depending on the reconfiguration status, the antenna can operate on different wireless communication systems, such as Bluetooth and Wi-Fi (2.40 $\mathrm{GHz}$ at $2.483 \mathrm{GHz}$ ), multimedia communication (SCM), personal mobile (SMP) systems (3.4 GHz to 3.6 GHz), earth exploration satellite systems, space research, radiolocation or aeronautical radionavigation ( $5.35 \mathrm{GHz}$ to $5.46 \mathrm{GHz}$ ).

Results for the reflection coefficient as function of frequency, bandwidth, resonant frequency and VSWR were simulated using Ansoft HFSS. A prototype was fabricated and measured for comparison purpose. Good agreement between simulation and measurement results was verified.

\section{ANTENNA SYNTHESIS}

The antenna geometry is based on the tetra-circle fractal. This fractal is based on a larger central circle and other four circles which radii are half of the central circle radius. These four circles are centered equidistantly at the end of the larger circle, divided into four congruent arcs, as shown in Fig. 1.

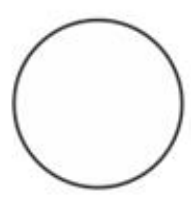

(a)

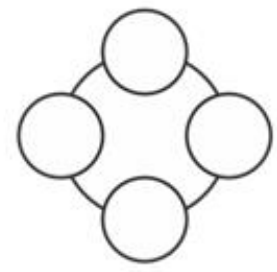

(b)



(c)

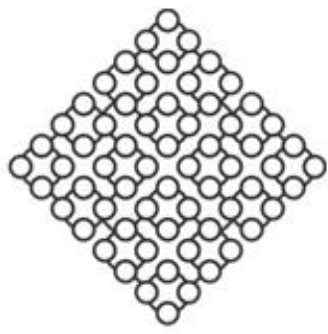

(d)

Fig. 1. Tetra-circle fractal geometries with different iteration levels. (a) $\mathrm{N}=0$, (b) $\mathrm{N}=1$, (c) $\mathrm{N}=2$, and (d) $\mathrm{N}=3$.

The proposed microstrip antenna patch geometry based on tetra-circle fractal of iteration level $\mathrm{N}=2$ is shown in Fig. 2. The patch central circle radius is $r_{a}$ and the small circles radius are $r_{a} / 4$. The 
microstrip dimensions are width, $\mathrm{W}_{\mathrm{L}}$, and length, $\mathrm{L}_{\mathrm{L}}$, and the dielectric substrate parameters are relative permittivity, $\varepsilon_{r}$, and substrate height, h. A tri-circle geometry was used to reduce the patch antenna size and use a microstrip line feed.

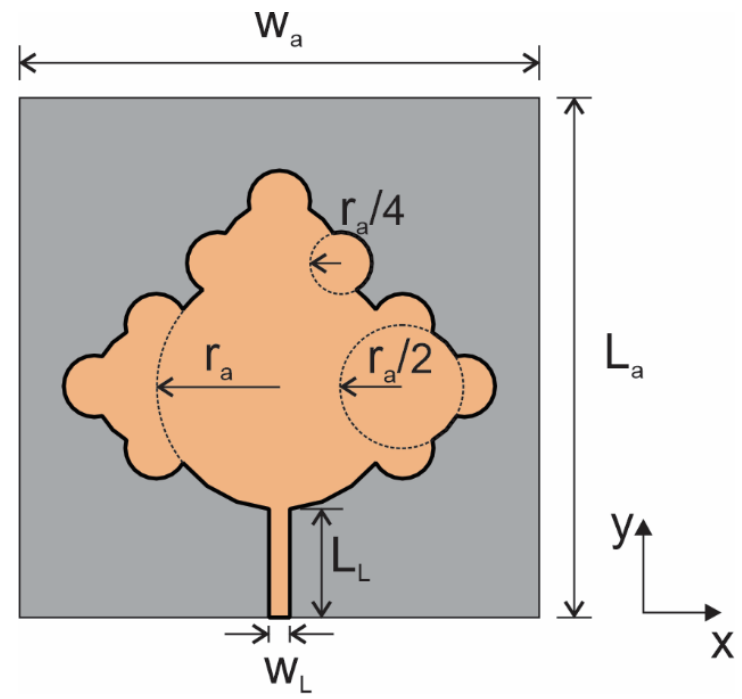

Fig. 2. Proposed microstrip antenna patch geometry based on the tetra-circle fractal of iteration level 2.

In this work, the synthesis of a tetra-circle fractal resonator is based on the statistical technique of the response surface methodology (RSM method). This technique is widely used in the modeling and analysis of problems in which the response depends on many variables [7].

The RSM method consists of finding an approximate equation to relate the desired response and the factors that interfere with it. This equation must lead to an optimal value (maximum, minimum or target) of the response [8]. The first step in this methodology is to find out an adequate approximation for the relationship between the independent variables and the dependent variable. Normally, a low order polynomial [8] is used.

Assuming the expected response $y$ as a function of $k$ independent variables $x_{1}, x_{2}, \ldots, x_{k}$, the relationship between $y$ and the independent variables can be described as first-order, second-order or higher order polynomials [7], [8], as shown below.

$$
\begin{aligned}
& y=\beta_{0}+\sum_{i=1}^{k} \beta_{i} x_{i}+\epsilon \\
& y=\beta_{0}+\sum_{i=1}^{k} \beta_{i} x_{i}+\sum_{i=1}^{k} \beta_{i i} x_{i}^{2}+\sum_{i<j} \sum \beta_{i j} x_{i} x_{j}+\epsilon
\end{aligned}
$$

In (1) and (2), for the calculation of the $\beta$ values, the least squares method is used. The response surface methodology was used to relate the structural parameters of a microstrip antenna with its resonant frequency, $f_{r}$, to obtain a synthesis approximate expression. The antenna structural parameters are: radius of the larger patch, $r_{a}$, substrate height, $h$, and relative 
permittivity, $\varepsilon_{r}$. The data for this statistical modelling were obtained using Ansoft HFSS simulations in a three steps parametric analysis.

In the first step, the relative permittivity is 4.4 , the substrate height is $1.57 \mathrm{~mm}$, and the patch radius, $r_{a}$, is varied from 8 to $18(\mathrm{~mm})$. The effect on the antenna resonant frequency, $f_{r}$, is shown in Fig. 3 and is inversely proportional to the antenna larger patch radius, $r_{a}$.

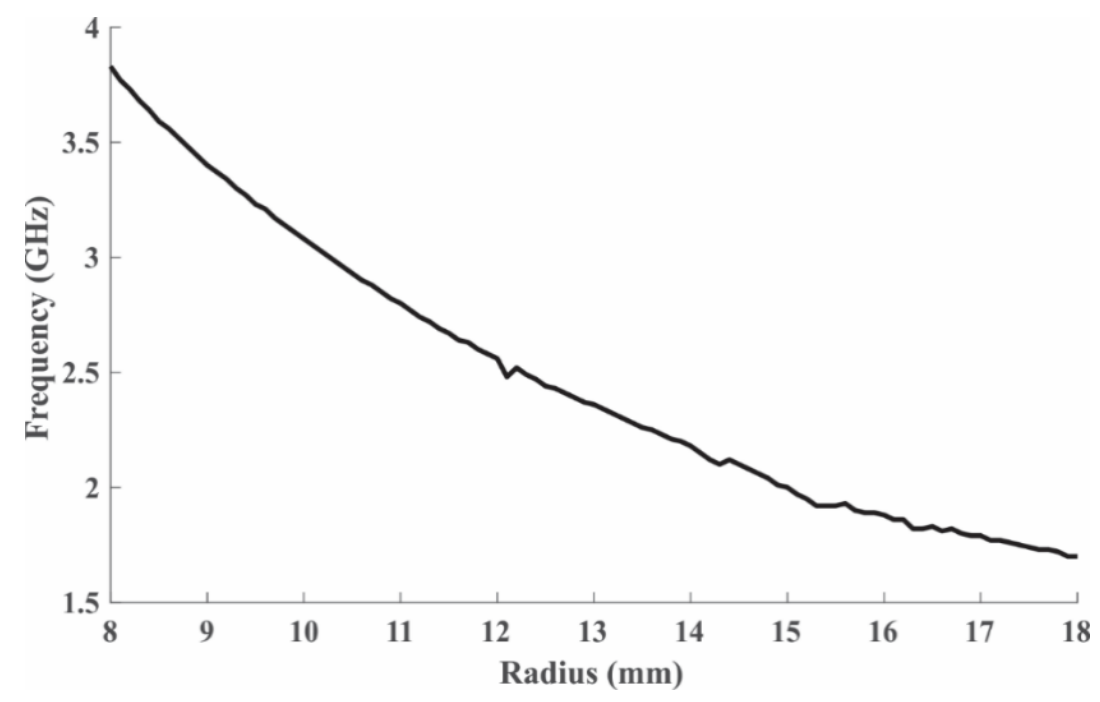

Fig. 3. Resonant frequency as function of the antenna higher patch radius, $\mathrm{r}_{\mathrm{a}}$.

In the second step, the substrate relative permittivity is 4.4 , the larger patch radius is $12.0 \mathrm{~mm}$, and the substrate height is varied from 0.5 to $10(\mathrm{~mm})$. The effect on the antenna resonant frequency, $f_{r}$, is shown in Fig. 4.

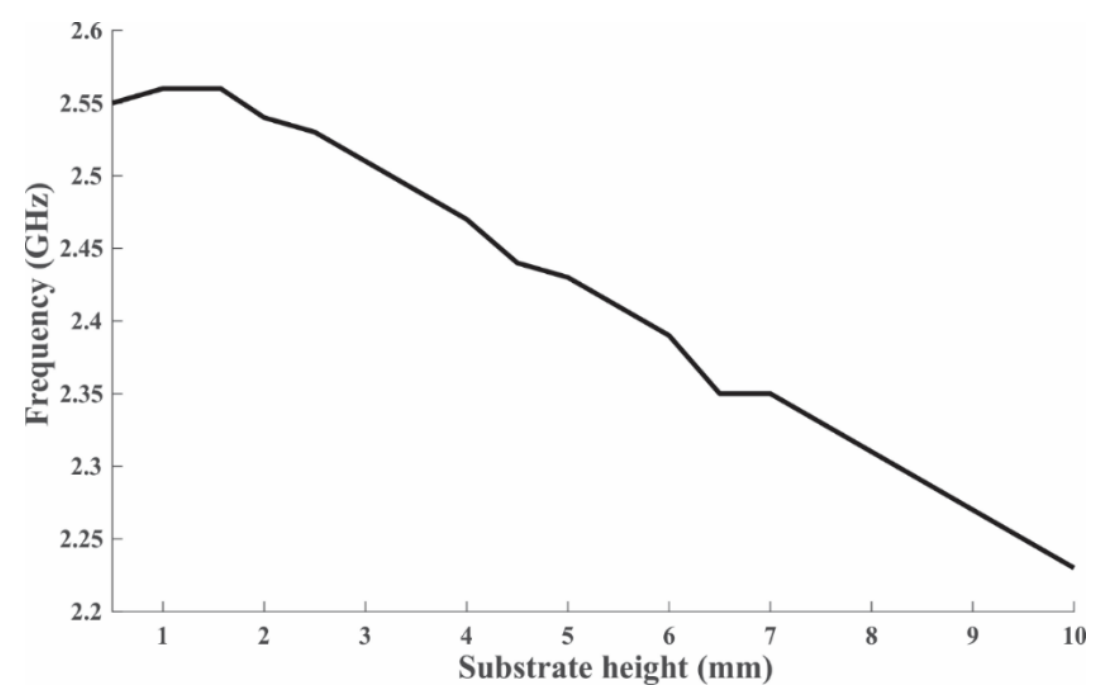

Fig. 4. Resonant frequency as a function of the antenna substrate height. 
In the third step, the higher patch radius is $12.0 \mathrm{~mm}$, the substrate height is $1.57 \mathrm{~mm}$ and the relative permittivity is varied from 1 to 10 . The effect on the antenna resonant frequency, $f_{r}$, is shown in Figure 5 and is inversely proportional to the relative permittivity value.

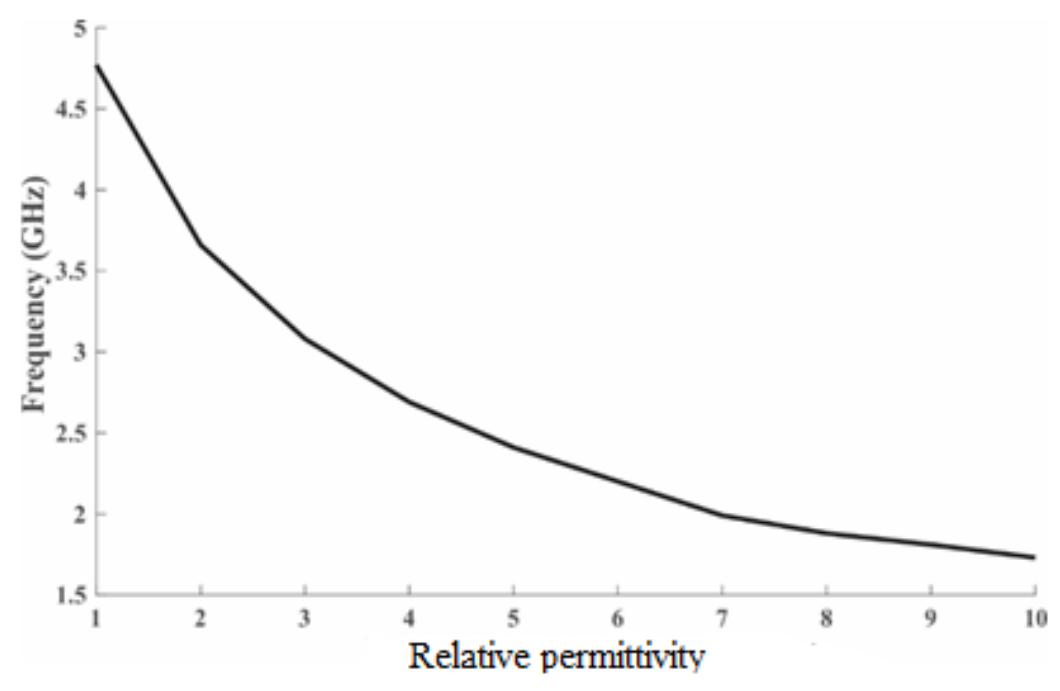

Fig. 5. Resonant frequency as function of the antenna relative permittivity.

With the objective of developing a synthesis approximate expression for the proposed microstrip antenna, the larger patch radius, $r_{a}$, was adopted as the dependent variable while the resonant frequency, $f_{r}$, substrate height, $h$, and relative permittivity, $\varepsilon_{r}$, were chosen as independent variables.

For a linear model analysis, the approximate expression shown in (3) was obtained, where $f_{r}$ is given in $\mathrm{GHz}, r_{a}$ and $h$ in $\mathrm{mm}$, and $\varepsilon_{r}$ is dimension less, enabling a coefficient of determination of 0.7919, i.e., $79.19 \%$ of the data could be explained by the approximate expression, an unsatisfactory result.

$$
r_{a}=-4.17840 f_{r}-0.26175 h-1.08494 \varepsilon_{r}+29.16657
$$

For a second-order model analysis, the approximate expression shown in (4) was obtained. In this case, a greater degree of reliability was obtained with a coefficient of determination of 0.9699 , which means that $96.99 \%$ of the simulated data could be explained by the proposed approximate expression, for $8 \leq r_{a} \leq$ to $18(\mathrm{~mm}), 0.5 \leq h \leq 10(\mathrm{~mm})$, and $1 \leq \varepsilon_{r} \leq 10$.

$$
\begin{array}{r}
r_{a}=-8.86262 f+0.36629 h-3.10208 \varepsilon_{r}+0.71533 f^{2}-0.01577 h^{2}+0.15961 \varepsilon_{r}^{2}- \\
0.18402 f h+0.06191 f \varepsilon_{r}+39.86262
\end{array}
$$

The residuals of this model had an average square of 0.2957 , showing an excellent agreement between predicted and simulated Ansoft HFSS results. In addition, the model has no lack of adjustment. 


\section{ANTENNA DESIGN}

A prototype of the proposed microstrip patch antenna based on the tetra-circle fractal geometry of iteration level 2 , with a modified shape to simplify the antenna feeding and reduce its size, is shown in Fig. 6.

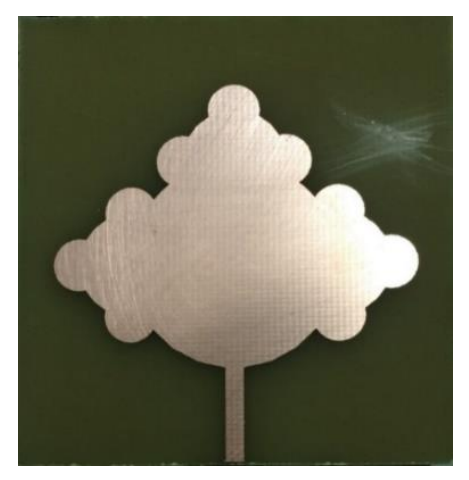

Fig. 6. Photograph of the proposed microstrip antenna prototype based on tetra-circle fractal of iteration level 2.

Using (4), the value of the radius, $r_{a}$, of the larger circle, illustrated in Fig. 5(a), can be determined as function of the microstrip antenna resonant frequency, $f_{r}$, and a dielectric substrate with thickness, $h$, ranging from $0.5 \mathrm{~mm}$ to $10 \mathrm{~mm}$, and relative permittivity, $\varepsilon_{r}$, varying from 1 to 10 .

Thereafter, the proposed tetra-circle fractal geometry was used in the development of a microstrip antenna on FR-4 substrate $\left(\varepsilon_{r}=4.4, \tan \delta=0.02, h=1.57 \mathrm{~mm}\right)$. The structural parameters of the proposed antenna, indicated in Fig. 2, were determined using (4), for a resonant frequency, $f_{r}$, of $2.459 \mathrm{GHz}$, resulting in $r_{a}=12.5 \mathrm{~mm}$.

Usually, planar microstrip antennas, composed of conducting patches printed on a grounded dielectric layer present narrow band and low gain characteristics. These antennas resonant frequencies depend on the conducting patch shapes and dimensions, and on the dielectric substrate relative permittivity $\left(\varepsilon_{r}\right.$, $\tan \delta$ ) and thickness ( $h$ ) knowledge to calculated the microstrip structure effective permittivity, $\varepsilon_{\text {reff }}$, and wavelength, $\lambda_{m}$, values, as well as the antenna resonant frequency, input impedance and reflection coefficient $\left(S_{11}\right)$ frequency response.

Recently, a great interest has been observed in the development of reconfigurable antennas for wireless communication system applications. The proposed antenna is mechanically reconfigurable enabling resonant frequency, gain, and radiation pattern changes through the ground plane tilting, as illustrated in Fig. 7(a) and shown in Fig. 7(b).

Moreover, the tilting of the microstrip antenna ground plane, modifies antenna dielectric substrate structure, due to the insertion of a new dielectric region filled with air (like a dielectric wedge), constituting a microstrip substrate with two layers and changing the previous effective permittivity, $\varepsilon_{\text {reff }}$, and wavelength, $\lambda_{m}$, into $\varepsilon^{\prime}{ }_{r e f f}$ and $\lambda^{\prime}{ }_{m}$, respectively, along with the antenna resonant frequency, Brazilian Microwave and Optoelectronics Society-SBMO received 26 Sept 2019; for review 10 Oct 2019; accepted 9 Apr 2020 $\begin{array}{llll}\text { Brazilian Society of Electromagnetism-SBMag } & \text { (c) } 2020 \text { SBMO/SBMag } & \text { (cc) BY } & \text { ISSN 2179-1074 }\end{array}$ 
bandwidth, and gain pattern, for example. In this case, the FR-4 substrate structure and conducting patch shape and dimensions considered in the design of the antenna prototype shown in Fig. 6, are kept constant.

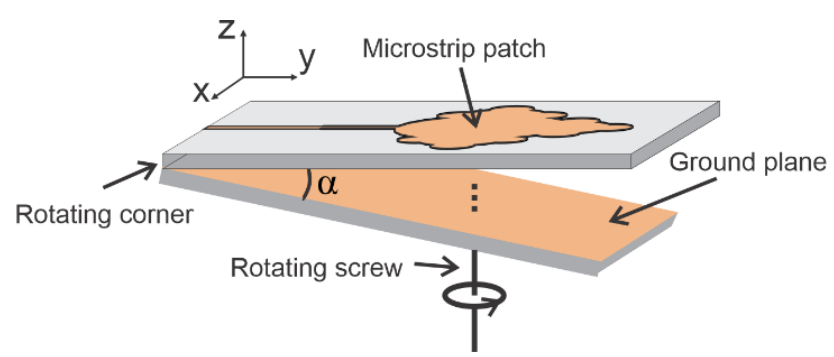

(a)

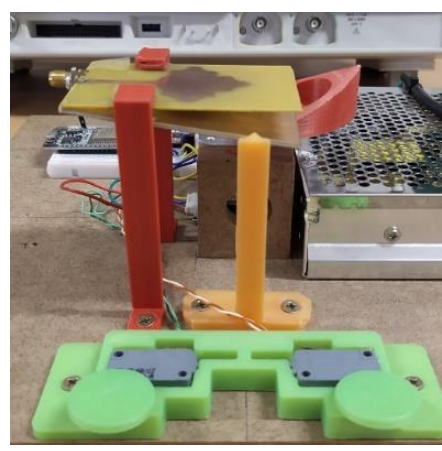

(b)

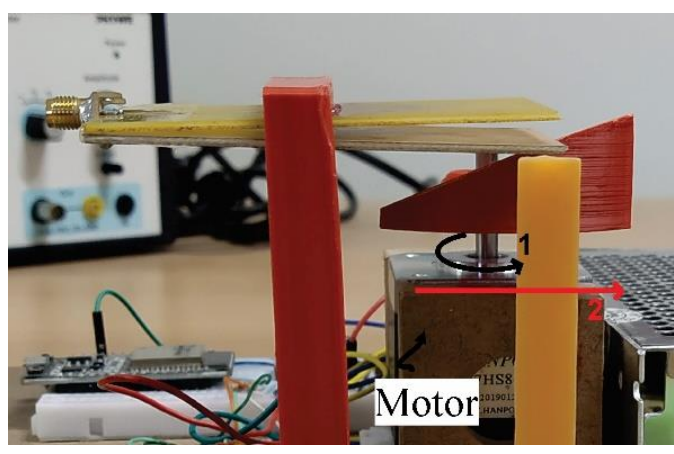

(c)

Fig. 7. Mechanically reconfigurable antenna structure. (a) Illustration; (b) Prototype photograph $\left(\alpha=10^{\circ}\right)$; (c) Prototype photograph $\left(\alpha=2^{\circ}\right)$.

In Fig. 7(b) and (c), a small DC motor is used to move right or left a dielectric ramp coupled to a motor axis rotation. Depending on the orientation of the motor axis rotation, the ramp pushes the antenna ground plane up or down, decreasing or increasing the tilt angle $\alpha$ value, respectively. This enables the antenna to operate at specific resonant frequencies for different wireless communication applications.

\section{RESULTS AND DISCUSSION}

Fig. 8 shows the proposed antenna reflection coefficient simulated and measured results at $\alpha$ $=0^{\circ}$ (without tilting the ground plane). The HFSS simulation results are resonant frequency, $f_{r}$ $=2.459 \mathrm{GHz}$, reflection coefficient, $\mathrm{S}_{11}(\mathrm{~dB})=-34.90$, and relative bandwidth, $\mathrm{BW}(\%)=2.89$. Measurement results are, $f_{r}=2.457 \mathrm{GHz}, \mathrm{S}_{11}(\mathrm{~dB})=-28.52$, and $\mathrm{BW}(\%)=3.46 \%$. 


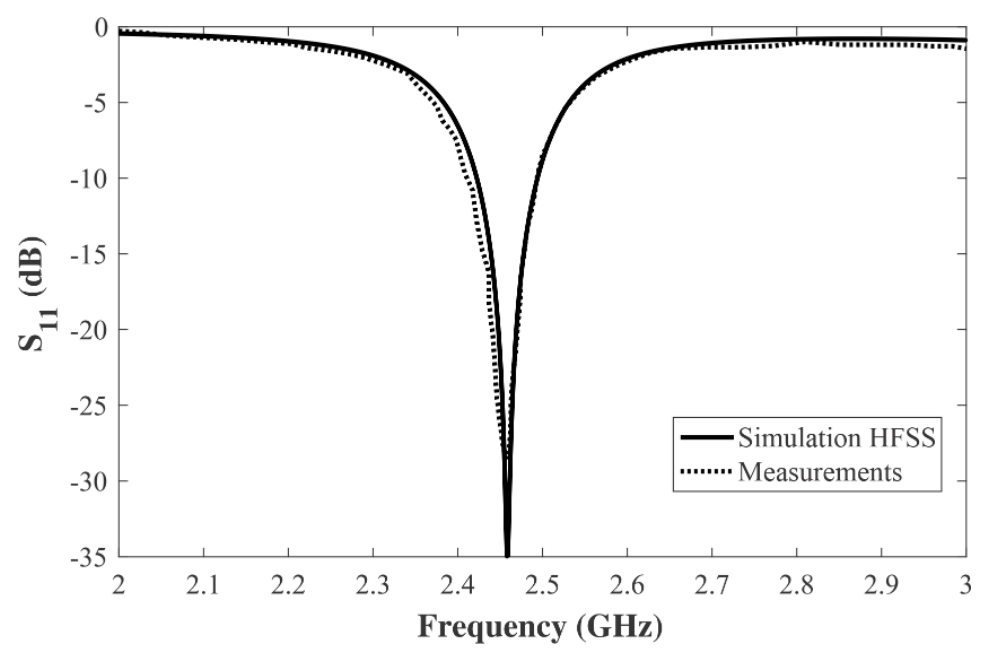

Fig. 8. Simulation and measurements reflection coefficient results of the proposed antenna at $\alpha=0^{\circ}$.

Fig. 9 shows HFSS simulated (gain) radiation pattern at the frequency of $2.459 \mathrm{GHz}$ for both co- and cross-polarization for $\alpha=0^{\circ}$ (without tilting the ground plane). As shown in Fig. 9, in all cases, the cross-polarization results are $16 \mathrm{~dB}$ lower than the co-polarization ones. In addition, the surface current density HFSS simulated results at $2.459 \mathrm{GHz}$ are shown in Fig. 10.

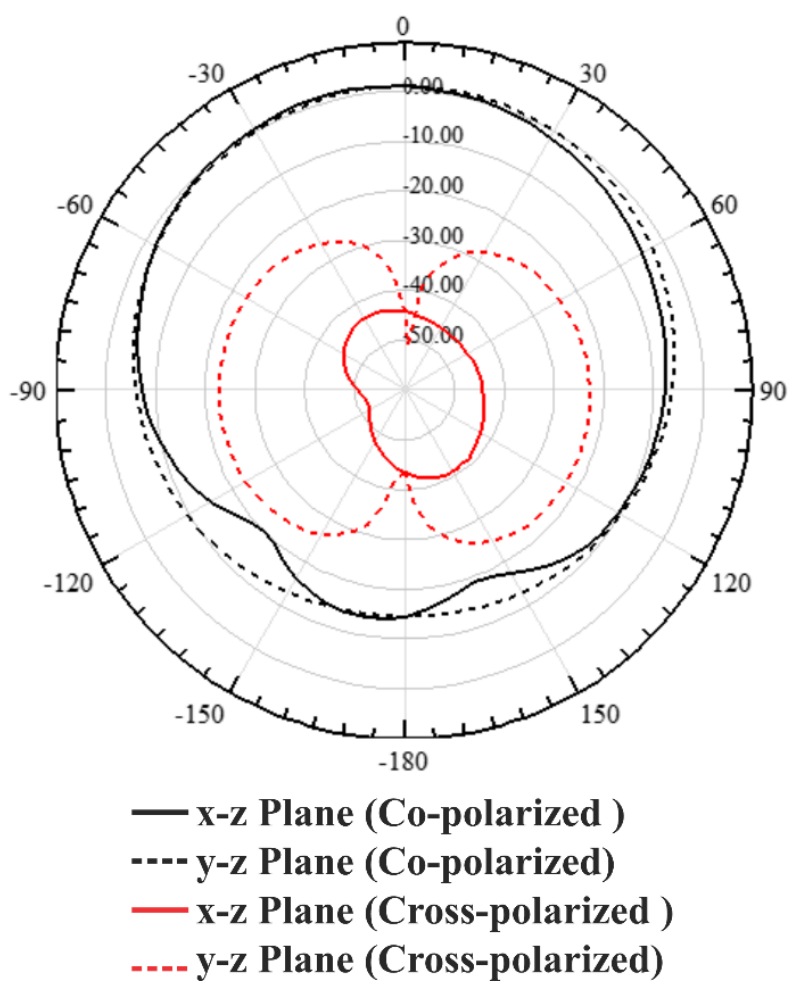

Fig. 9. Simulation 2D gain pattern results of the proposed antenna at $\alpha=0^{\circ}$. 


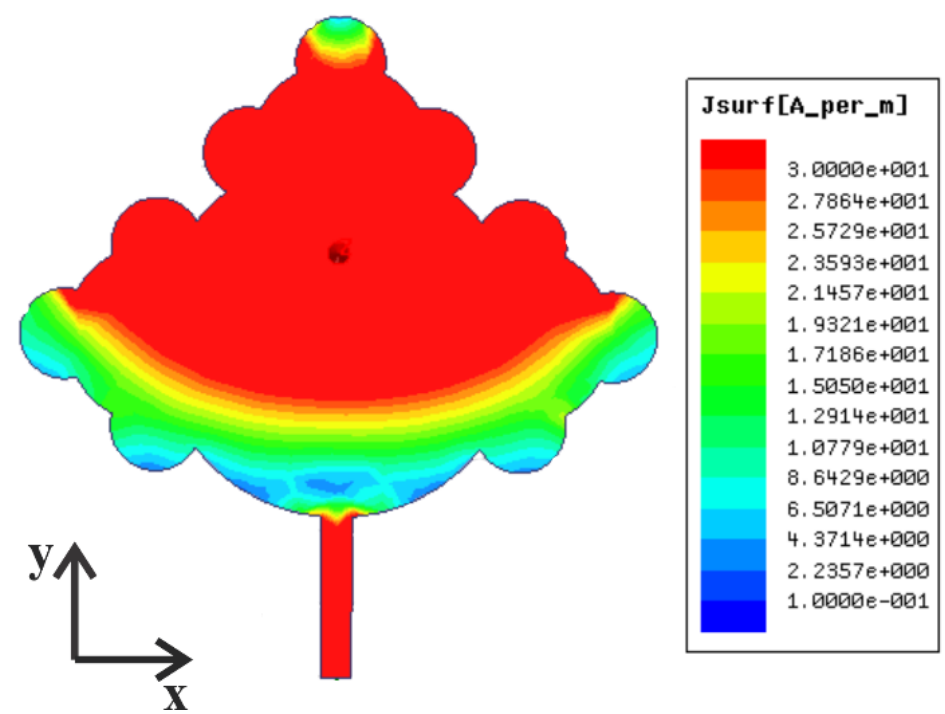

Fig. 10. HFSS surface current density on the patch of the proposed antenna at $\alpha=0^{\circ}$. Resonant frequency is $2.459 \mathrm{GHz}$.

Fig. 11 shows the simulated reflection coefficient results of the proposed antenna at different values $\left(0^{\circ}, 2^{\circ}\right.$, and $\left.10^{\circ}\right)$ of the tilt angle, $\alpha$, for the frequency range from 1 to $6 \mathrm{GHz}$, for comparison purpose. At $\alpha=0^{\circ}$, a dual-band response is obtained. The first resonance band results are $f_{r, 1}=2.459 \mathrm{GHz}$, $\mathrm{S}_{11,1}(\mathrm{~dB})=-18.0$, and $\mathrm{BW}_{1}(\%)=2.42$, and the second resonance band results are $f_{r, 2}=4.62 \mathrm{GHz}$, $\mathrm{S}_{11,2}(\mathrm{~dB})=-13.9$, and $\mathrm{BW}_{2}(\%)=1.73$.

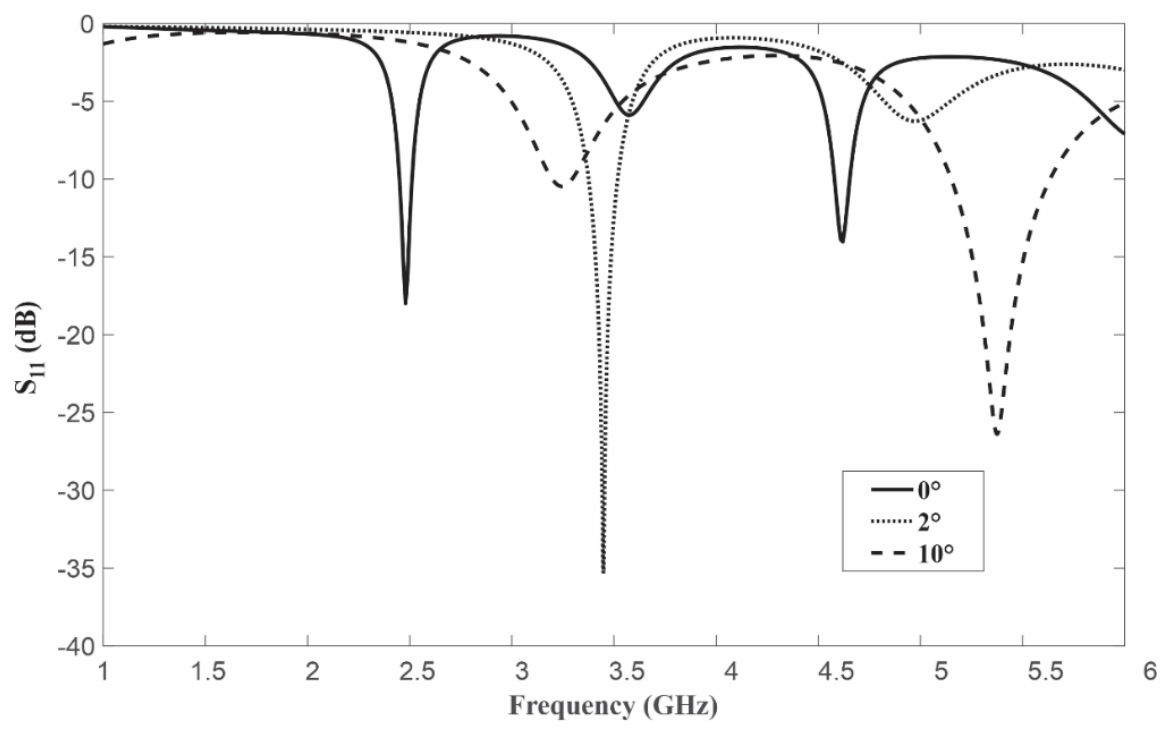

Figure 11. Simulation reflection coefficient results of the proposed antenna at $\alpha=0^{\circ}, 2^{\circ}$, and $10^{\circ}$.

At a tilt angle of $2^{\circ}$, a single band response is observed with a higher resonant frequency, corresponding to both number of resonant modes and resonant frequency reconfigurations. In addition, at $\alpha=2^{\circ}$, the resonance band results are $f_{r, 1}=3.447 \mathrm{GHz}, \mathrm{S}_{11,1}(\mathrm{~dB})=-34.98$, and $\mathrm{BW}_{1}(\%)=4.11$. 
At $\alpha=10^{\circ}$, a single band response is obtained. The resonance band results are $f_{r, l}=5.381 \mathrm{GHz}$, $\mathrm{S}_{11,1}(\mathrm{~dB})=-26.26$, and $\mathrm{BW}_{1}(\%)=8.88$.

Comparisons between simulated and measured reflection coefficient results of the proposed antenna with different values of the tilt angle, $\alpha$, are shown in Fig. 12.

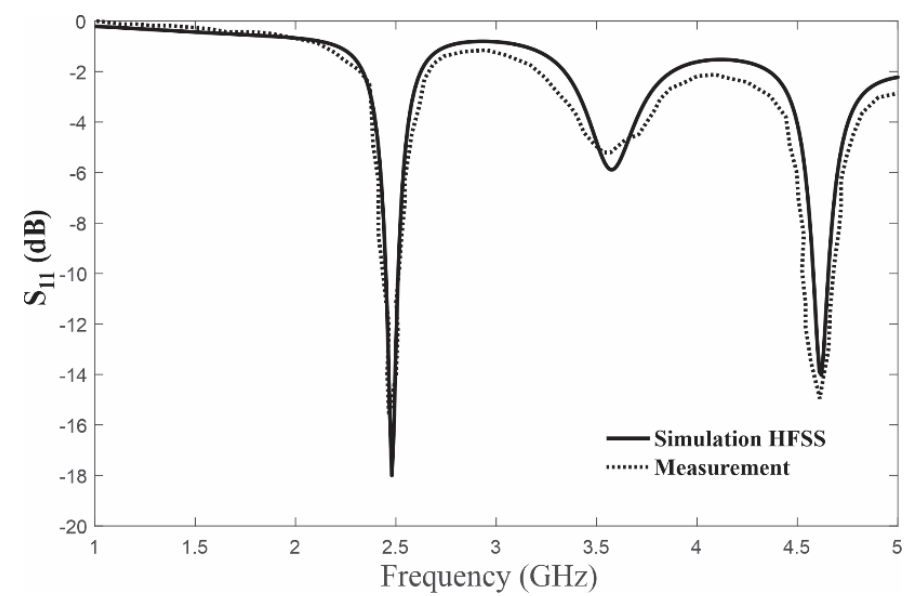

(a)

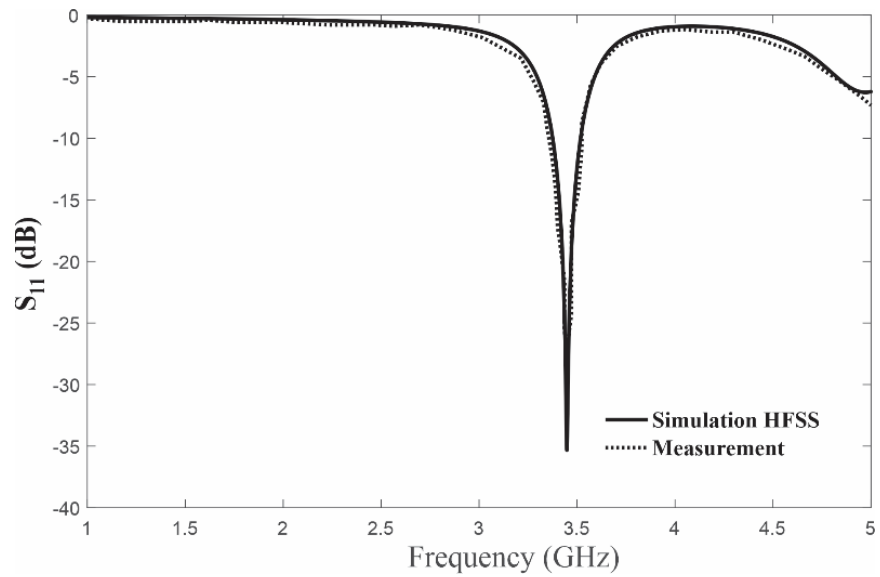

(b)

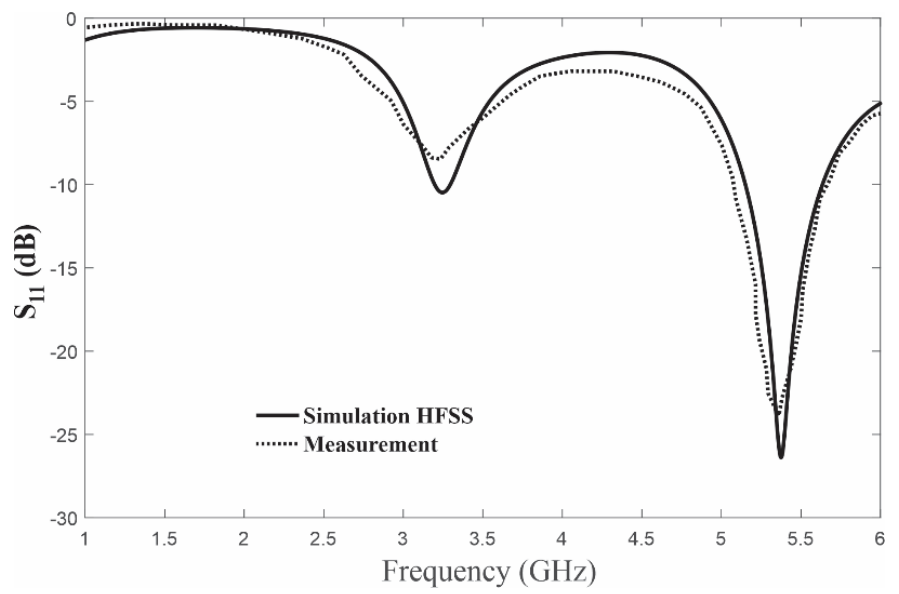

(c)

Fig. 12. Simulated and measured reflection coefficient results for the proposed reconfigurable antenna at different tilt angles. (a) $0^{\circ}$, (b) $2^{\circ}$, and (c) $10^{\circ}$. 
Therefore, the proposed reconfigurated antenna can operate in Bluetooth and Wi-Fi systems $(2.40$ $\mathrm{GHz}$ at $2.483 \mathrm{GHz}$ ) when the tilt angle is $0^{\circ}$. It can also operate in multimedia communication (SCM), personal mobile (SMP) or amateur radio $(3.4 \mathrm{GHz}$ at $3.6 \mathrm{GHz})$ systems, the tilt angle is $2^{\circ}$. In addition, it can also operate in earth exploration satellite systems, space research, radiolocation or aeronautical radionavigation $(5.35 \mathrm{GHz}$ at $5.46 \mathrm{GHz})$.

Table I summarizes the simulated and measured results for the proposed antenna which are in a good agreement.

TABLE I. SIMULATED AND MEASURED RESULTS OF THE PROPOSED ANTENNA

\begin{tabular}{|c|c|c|c|c|c|c|}
\hline \multirow{2}{*}{$\boldsymbol{\alpha}$} & \multicolumn{2}{|c|}{$\boldsymbol{f}_{\boldsymbol{r}}(\mathbf{G H z})$} & \multicolumn{2}{c|}{ BW $(\mathbf{\%})$} & \multicolumn{2}{c|}{$\mathbf{S}_{11}(\mathbf{d B})$} \\
\cline { 2 - 7 } & HFSS & Measured & HFSS & Measured & HFSS & Measured \\
\hline $0^{\circ}\left(1^{\text {st }}\right.$ band $)$ & 2.459 & 2.466 & 2.42 & 2.45 & -18.00 & -15.62 \\
\hline $0^{\circ}\left(2^{\text {nd }}\right.$ band $)$ & 4.620 & 4.611 & 1.73 & 3.45 & -13.90 & -14.95 \\
\hline $2^{\circ}\left(1^{\text {st }}\right.$ band $)$ & 3.447 & 3.444 & 4.11 & 4.13 & -34.98 & -27.65 \\
\hline $10^{\circ}\left(1^{\text {st }}\right.$ band $)$ & 5.381 & 5.360 & 8.88 & 11.49 & -26.26 & -23.88 \\
\hline
\end{tabular}

According to Table I results, an increasing of the tilt angle shifts the resonant frequency to a higher value and increases the antenna bandwidth.

Simulation results for the reconfigurable antenna gain pattern are shown in Figure 13 at different values of the tilt angle: (a) $0^{\circ}$, (b) $2^{\circ}$, and (c) $10^{\circ}$. Gain patterns show that the antenna is directional in the considered cases with different tilt angles. Also, in the cases where the tilt angle is $2^{\circ}$ or $10^{\circ}$, the antenna gain has increased compared to the case without tilting the ground plane $\left(\alpha=0^{\circ}\right)$. In addition, the antenna half-power beamwidth has remained almost constant in the $\mathrm{x}-\mathrm{z}$ elevation plane and has decreased in the $y-z$ elevation plane. Table II presents the results for antenna gain and half-power beam, for different tilt angles. 


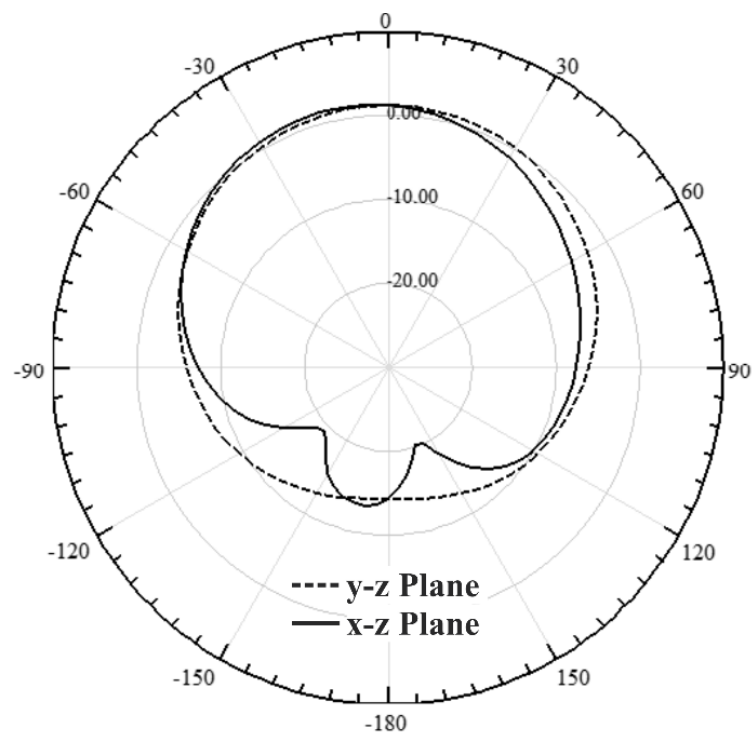

(a)

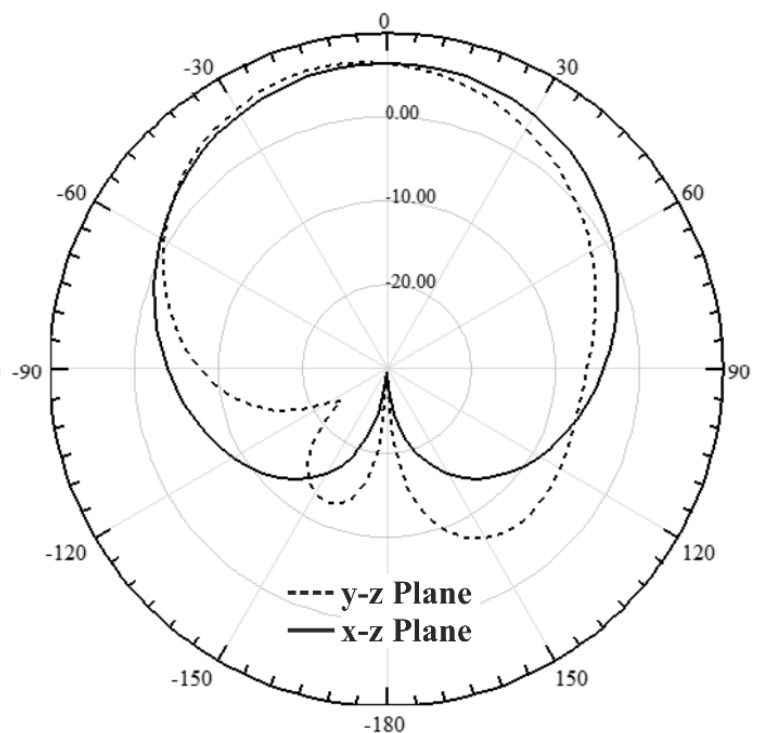

(b)

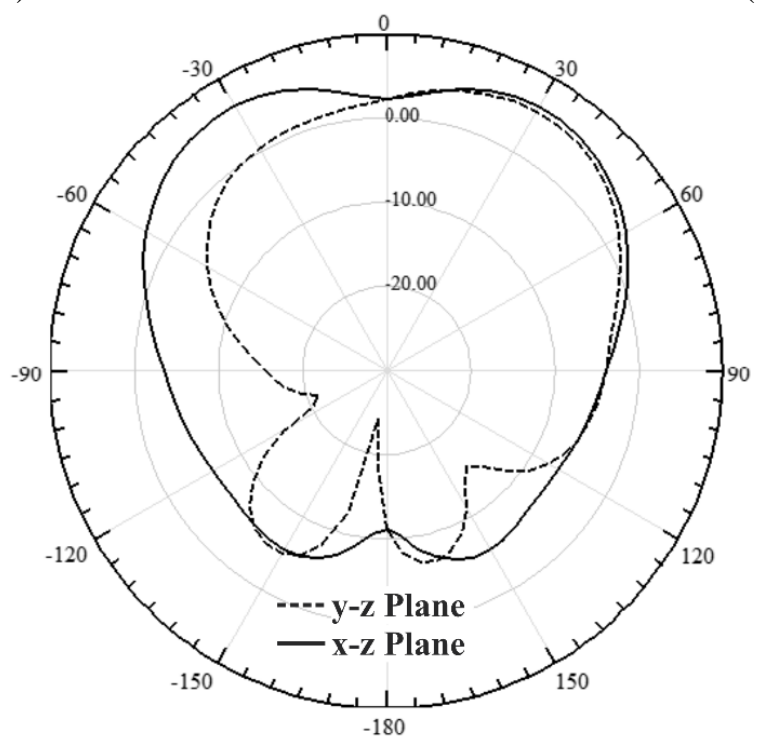

(c)

Fig. 13. Simulated gain pattern results of the reconfigurable antenna at different incident angles: (a) $\alpha=0^{\circ}$, at $2.459 \mathrm{GHz}$; (b) $\alpha=2^{\circ}$, at $3.447 \mathrm{GHz}$; and (c) $\alpha=10^{\circ}$, at $5.381 \mathrm{GHz}$.

TABLE II. RADIATION PATTERN RESULTS AT DIFFERENT TILT ANGLES

\begin{tabular}{|c|c|c|c|c|}
\hline \multirow{2}{*}{$\boldsymbol{\alpha}$} & \multicolumn{2}{|c|}{ Maximum Gain (dB) } & \multicolumn{2}{c|}{ Half-Power Beamwidth } \\
\hline $\mathbf{0}^{\circ}$ & x-z plane & y-z plane & x-z plane & y-z plane \\
\hline $\mathbf{2}^{\mathbf{0}}$ & 1.27 & 1.27 & $90^{\circ}$ & $110^{\circ}$ \\
\hline $\mathbf{1 0}^{\mathbf{o}}$ & 6.48 & 6.48 & $85^{\circ}$ & $75^{\circ}$ \\
\hline
\end{tabular}

The simulated radiation efficiency values were obtained in HFSS, for $\alpha=0^{\circ}$ the efficiency is 0.40 , for $\alpha=2^{\circ}$ it was 0.8433 and in the case of $\alpha=10^{\circ}$ the efficiency was 0.9371 . 


\section{CONCLUSION}

An investigation on the properties of tetra-circle fractal inspired microstrip antennas with tilted ground plane was presented enabling to achieve reconfiguration of the resonant frequencies and radiation pattern performance. The tetra-circle patch shape enables an easy design based on the knowledge of the radius of the larger circle, $r_{a}$, from which the other key dimensions are obtained, simplifying the antenna synthesis. The synthesis simulation was performed using a simple expression for $r_{a}$ calculation which was obtained using Ansoft HFSS software and the response surface methodology.

The proposed synthesis expression for $r_{a}$ calculation provided accurate resultswhen used in microstrip antenna designs. A prototype of the reconfigurable microstrip antenna was designed and measured at tilt angles of $0^{\circ}, 2^{\circ}$ and $10^{\circ}$, for comparison purpose. The antenna presented different resonant frequencies for each angle, confirming the antenna reconfiguration ability. At $2^{\circ}$ and $10^{\circ}$ tilting angles, the antenna presented a high gain and became more directive. A small DC motor was used to tilt the antenna ground plane up and down. Simulated and measured results are in agreement. The proposed reconfigurable antenna can operate in different systems according to the resonant frequency values related to the tilting ground plane angle, $\theta$. At $\alpha=0^{\circ}$, the antenna could be used in Bluetooth and WiFi systems. At $\alpha=2^{\circ}$, the antenna could be used in multimedia communication (SCM), personal mobile (SMP) or amateur radio. At $\alpha=10^{\circ}$, it could be used in earth exploration satellite systems, space research, radiolocation or aeronautical radionavigation.

\section{REFERENCES}

[1] C. X. Mao, S. Gao, and Y. Wang, "Broadband high-gain beam-scanning antenna array for millimeter-wave applications," IEEE Trans. Antennas Propag. vol. 65, no. 9, pp. 4864-4868, 2017.

[2] B. Singh, N. Sarwade, and K. P. Ray, "Compact series fed tapered antenna array using unequal rectangular microstrip antenna elements," Microw. Opt. Technol. Lett., vol. 59, no. 8, pp. 1856-1861, 2016.

[3] H. L. Zhu, S. W. Cheung and T. I. Yuk, "Mechanically pattern reconfigurable antenna using metasurface," IET Microwaves, Antennas \& Propagation, vol. 9, no. 12, pp. 1331-1336, 2015.

[4] K. Noda, M. Ohkado, B.-K. Nguyen, K. Matsumoto, H. Fujikawa, and I. Shi, "Frequency-tunable microstrip antenna with liquid actuator using gradually widened transmission line," IEEE Antennas and Wirel. Propag. Lett., vol. 14, pp. 551$555,2015$.

[5] J. F. Tsai and J. S. Row, "Reconfigurable square-ring microstrip antenna," IEEE Trans. Antennas Propag., v. 61, no. 5, pp. 2857-2860, 2013.

[6] D. Singh, B. Kanaujia, S. Dwari, G. Pandey, and S. Kumar, "Reconfigurable circularly polarized capacitive coupled microstrip antenna," Int.J. Microw. Wirel. Technol., vol. 9 n. 4, p. 843-850, 2017.

[7] A. I. Khuri and S. Mukhopadhyay, "Response surface methodology," WIREs Comput. Stat., vol. 2, 2010, pp. $128-149$.

[8] R. H. Myers, I. K. André, and H. C. Walter, “Response surface methodology: 1966-1988," Technometrics, vol. 31, pp. 137-157, 1989.

[9] J. Costantine, Y. Tawk, S. E. Barbin, and C. G. Christodoulou, "Reconfigurable antennas: design and applications," Proc. IEEE, vol. 103, pp. 424-437, 2015.

[10] C. A. Balanis, Antenna Theory - Analysis and Design, Harper \& Row, Pub., New York, 1982.

[11] J. Deng, S. Hou, L. Zhao, and L. Guo, "A Reconfigurable filtering antenna with integrated bandpass filters for UWB/WLAN applications," IEEE Trans. Antennas Propag., vol. 66, pp. 401-404, 2018.

[12] L. Pazin and Y. Leviatan, "Reconfigurable rotated-T slot antenna for cognitive radio systems," IEEE Trans. Antennas Propag., vol. 62, pp. 2382-2387, 2014.

[13] P. S. Neethu and T. Sudha, "Patch antenna for wireless LAN systems with polarization reconfigurability," Nat. Conf. Commun. Signal Proc. Networking (NCCSN), Palakkad, India, 2014, pp. 1-5.

[14] GuipingJin, Chengyan Li, Tao Zhou, "Frequency reconfigurable antenna for cognitive radio applications," IEEE Int. Conf. Commun. Problem-Solving (ICCP), Beijing, China, 2014, pp. 176-179.

Brazilian Microwave and Optoelectronics Society-SBMO received 26 Sept 2019; for review 10 Oct 2019; accepted 9 Apr 2020

$\begin{array}{llll}\text { Brazilian Society of Electromagnetism-SBMag } & \text { (c) } 2020 \text { SBMO/SBMag } & \text { (cc) BY } & \text { ISSN 2179-1074 }\end{array}$ 
[15] X.-L. Yang, J.-C. Lin, G. Chen and F.-L. Kong, "Frequency reconfigurable antenna for wireless communications using GaAs FET switch,” IEEE Antennas Wirel. Propag. Lett., vol. 14, pp. 807-810, 2014.

[16] J.-M. Hannula, J. Holopainen, and V. Viikari, "Concept for frequency-reconfigurable antenna based on distributed transceivers," IEEE Antennas Wireless Propag. Lett., vol. 16, pp. 764-767, 2017.

[17] S. Danesh, S. K. A. Rahim, M. Abedian, and M. R. Hamid, "A compact frequency-reconfigurable dielectric resonator antenna for LTE/WWAN and WLAN applications," IEEE Antennas Wirel. Propag. Lett., vol. 14, pp. 486-489, 2015.

[18] K. S. Ryu and A. A. Kishk, "Ultrawideband dielectric resonator antenna with broadside patterns mounted on a vertical ground plane edge," IEEE Trans. Antennas Propag., vol. 58, pp. 1047-1053, 2010.

[19] H. Rajagopalan, J. M. Kovitz, and Y. Rahmat-Samii, "MEMS reconfigurable optimized E-shaped patch antenna design for cognitive radio," IEEE Trans. Antennas Propag., vol. 62, pp. 1056-1064, 2014.

[20] P. Kakaria and R. Nema, "Review and survey of compact and broadband microstrip patch antenna," Int. Conf. Advances Eng.\& Technol. Res. (ICAETR), Unnao, India, 2014, pp. 1-5. 